\title{
Chromosomal mapping and expression of the human cyr61 gene in tumour cells from the nervous system
}

\author{
C Martinerie, E Viegas-Pequignot, V C Nguyen, B Perbal
}

\begin{abstract}
Aims-To characterise the human cyr61 gene (cyr61H) and determine its chromosomal locality. To compare expression of cyr61H in human tumour cell lines with that of two other structurally related genes, novH (nephroblastoma overexpressed gene) and CTGF (connective tissue growth factor), that are likely to play a role in the control of cell proliferation and differentiation.

Methods-To isolate the human cyr61 gene, placental genomic and HeLa cDNA libraries were screened with murine cyr61 cDNA. The nucleotide sequence of the complete cyr61H cDNA was established. Both Southern blotting of a panel of somatic cell hybrids and in situ hybridisation on chromosomes were performed to map the cyr61H gene. Expression of cyr61H, novH, CTGF, and novH was analysed by northern blotting in both human neuroblastomas and glioblastoma cell lines.
\end{abstract}

Results-Genomic and cDNA clones encompassing the cyr61H gene were isolated and characterised. Comparison of mouse and human cyr 61 sequences indicated that their genomic organisation is highly conserved. Alignment of coding sequences highlighted the conservation of cyr61 regions that might be critical for its biological function. The data showed that the cyr61H gene is assigned to chromosome $1 \mathrm{p} 22.3$ and that different levels of cyr61H, CTGF, and novH mRNA have been detected in several human tumour cell lines derived from the nervous system.

Conclusions-The human cyr61 gene belongs to an emerging family of genes including CTGF/fisp12 and nov. The murine cyr61 encodes an extracellular cysteine rich protein that exhibits chemotactic activity, promotes attachment and spreading of cells, and potentiates the mitogenic effect of growth factors. Assignment of the cyr61H gene to chromosome 1 22.3 will allow studies to determine whether human pathologies derived from the nervous system or from other tissues are associated with chromosomal abnormalities involving this region. Although the coding regions of cyr61H, CTGF, and novH are highly homologous, a growing body of evidence suggests that expression of these genes is regulated differentially, and that $a$ balance between expression of these genes might represent a key element in determining the stage of differentiation and/or the malignant potential of tumour cells.

(F Clin Pathol: Mol Pathol 1997;50:310-316)

Keywords: human cyr61; CTGF; nov; chromosome mapping; neuroblastomas; glioblastomas; nervous system tumours

The murine cyr61 gene was characterised as a growth factor inducible, immediate early gene in mouse fibroblasts. ${ }^{1}$ The CYR61 protein is a secreted, cysteine rich, heparin binding protein that associates with the cell surface and the extracellular membrane. ${ }^{2}$ The chicken homologue of cyr61 (CEF10) had been identified as an immediate early gene whose expression is induced by production of active $\mathrm{v}$-src in ts NY72-4 Rous sarcoma virus infected chicken embryo fibroblasts (CEF). Enhanced CEF10 RNA levels were also detected in serum treated normal fibroblasts. ${ }^{3}$

The CEF10/cyr61 genes share extended nucleotide sequence similarities with two groups of genes (fisp12/CTGF (connective tissue growth factor) and nov (nephroblastoma overexpressed gene)), ${ }^{4-9}$ encoding proteins likely to play a role in cell growth and/or differentiation. ${ }^{410}$ These genes also share more distant sequence similarities with two drosophila genes, twisted gastrulation and short gastrulation, which interact with decapentaplegic to regulate dorsal-ventral patterning. ${ }^{11}{ }^{12} \mathrm{~A}$ comparative analysis of the primary structures of CTGF/fisp12, cyr61/CEF10, and NOV established that these proteins contain 38 conserved cysteine residues and the following four structural motifs: (1) an insulin growth factor binding protein (IGFBP) module, highly homologous to the core $\mathrm{N}$-terminal IGF binding domain of previously described IGF binding proteins; (2) a Von Willebrand factor type C repeat (VWC) module likely to be involved in oligomerisation and represented in Von Willebrand factor; (3) a thrombospondin type I repeat (TSPI) module, represented in thrombospondin, and thought to be involved in the interaction with extracellular matrix molecules; and (4) a carboxy-proximal motif (CT) proposed to represent a dimerisation domain. ${ }^{13}$ Although the functionality of these domains remains to be established, it is tempting to propose that their conservation is related to the biological function(s) of these proteins. 
A

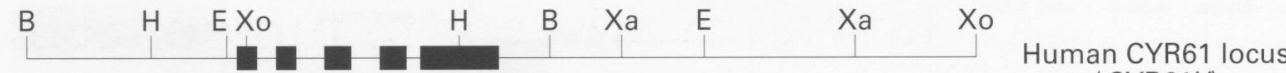

E1 E2 E3 E4 E5

(CYR61H)

pBB6.5

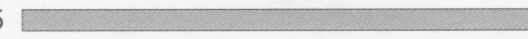

B

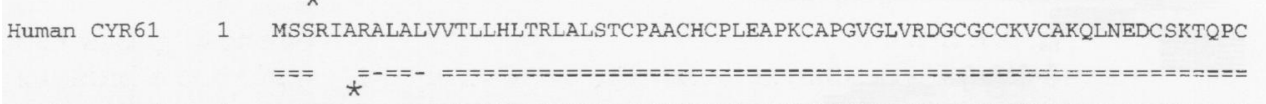

Murine CYR61 1 MSSSTFRTLAVAVTLLHLTRLALSTCPAACHCPLEAPKCAPGVGLVRDGCGCCKVCAKQLNEDCSKTQPC

Chicken CEF10 1 MGSAGARPALAAALLCLARLALGSPCPAVCQCPAAAPQCAPGVGLVPDGGCCKVCAKQLNEDCSRTQPC

\begin{abstract}
Human CYR61 71 DHTKGLECNFGASSTALKGICRAQSEGRPCEYNSRIYQNGESFQPNCKHQCTCIDGAVGCIPLCPQELSL
Murine CYR

DHTKGLECNFGASSTALKGICRAQSEGRPCEYNSRIYQNGESFQPNCKHQCTCIDGAVGCI PLCPQELSL

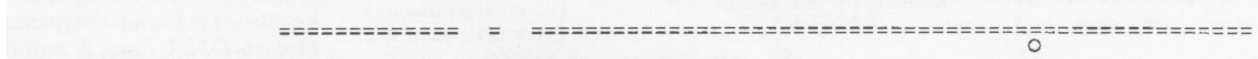

Chicken CEF10 71 DHTKGLECNFGASPAATNGICRAQSEGRPCEYNSKIYQNGESFQPNCKHQCTCIDGAVGCI PLCPQELSL
\end{abstract}

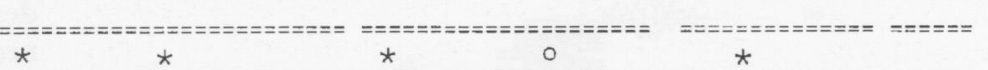

Figure 1 (A) Organisation of the human cyr61 gene. Partial restriction map of $\lambda H u 11$ and of the plasmid subclones pBB6.5 and pEE6.2. Probes: $p B B 6.5$ (6.5 kb BamHI fragment), pEE6.2 (6.2 kb EcoRI fragment). The position of exons in $\lambda H$ H 11 and the pBB6.5 and pEE6.2 subclones was mapped following Southern blotting with exon specific oligonucleotides as probes. The black boxes represent human exonic regions. Exons were numbered according to the nucleotide and amino acid sequences of the murine cyr61 gene. B, BamHI; E, EcoRI; H, HindIII; Xa, XbaI; Xo, XhoI. nucleotide and amino acid sequences of the murine cyr61 gene. $B, B a m H I ; E, E c o R I ; H, H i n d I I ;$
(B) Comparison of the murine, chick, and human cyr61 open reading frames (ORFs). Amino acid sequences from the human and murine cyr61 and chicken CEF10 proteins have been aligned to give maximal homology using the Clustal method. ${ }^{40}$ Conservative substitutions are indicated by a single line. The ${ }^{\star}$ and ${ }^{\circ}$ symbols represent predicted phoshorylation sites for protein kinase $C$ and casein kinase II, respectively.

In spite of their highly conserved organisation, the immediate-early CEF10/ cyr61 and fisp12/CTGF genes encode positive regulators of growth with distinct biological activities and are subject to different regulatory signals.
Both CTGF and CYR61 proteins exhibit chemotactic activities. ${ }^{414}$ CYR61 has been shown to promote cell adhesion and potentiate the mitogenic effects of growth factors such as $\beta$ fibroblast growth factor ( $\beta F G F)$ and platelet derived frowth factor B (PDGF B). ${ }^{14}$ CTGF, 

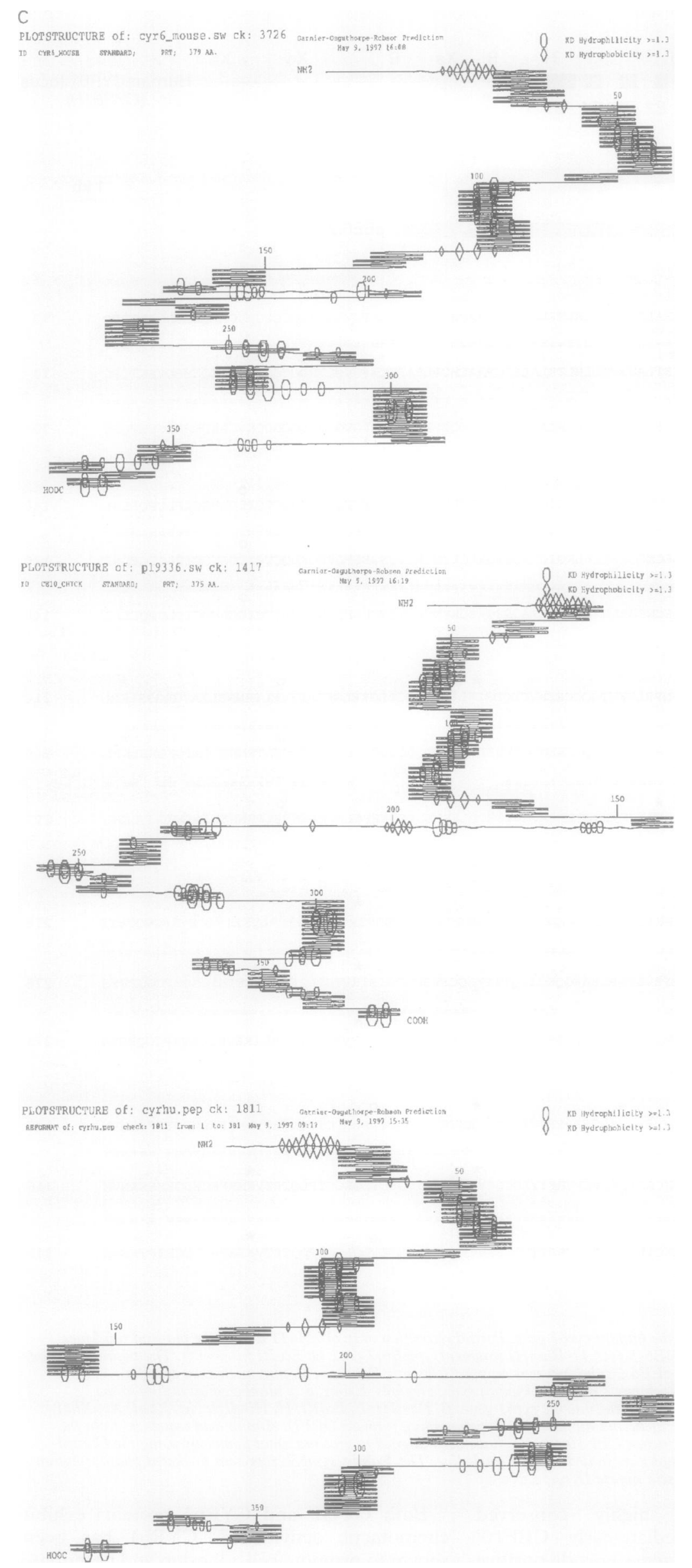

Figure 2 Predicted secondary structure according to Garnier et a ${ }^{30}$ of (top) murine CYR61 (cyr6-mouse), (middle) chicken CEF10 (p19336), and (bottom) human CYR61 (cyrhu).

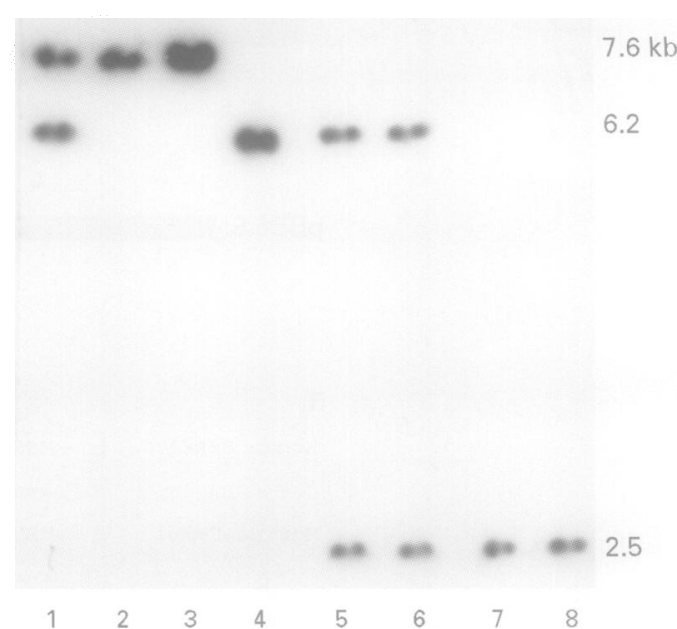

Figure 3 Detection of cyr61H specific sequences in human-rodent hybrid cell line DNA. Samples $(10 \mu \mathrm{g})$ were digested with EcoR1 restriction endonuclease, electrophoresed, transferred on to nylon membranes and hybridised with the ${ }^{32} \mathrm{P}$ labelled pcyr61 cDNA probe

(2.0 kb EcoR1 fragment). Lane 1, human-mouse hybrids positive for human sequences; lane 2, human-mouse hybrids negative for human sequences; lane 3, mouse DNA; lane 4, human DNA; lanes 5 and 6, human-hamster hybrids positive for human sequences; lane 7, human-hamster hybrids negative for human sequences; lane 8 , hamster DNA.

which was reported to act as a growth factor, ${ }^{4}$ is a downstream target of transforming growth factor $\beta$ (TGF $\beta){ }^{1516}$ We have shown previously $^{1017}$ that, in contrast to the other members of this gene family, nov is not an immediate-early gene. Its expression is associated with cell quiescence and is downregulated on induction of cell proliferation following treatment with serum and oncogenic transformation.

Because altered expression of nov has been shown to be associated with avian and human nephroblastoma ${ }^{67}$ (also Chevalier et al, unpublished), it is conceivable that an unbalanced expression of this gene's family may constitute a key point in the proliferation of tumour cells.

The observation that cyr61 expression corre- 을 lates with chondrogenesis during embryonic development ${ }^{18}$ and that nov expression is detected during embryogenesis of muscle, N nervous tissue, and cartilage ${ }^{19}$ (also Chevalier et $N$ al and Kocialkovski et al, unpublished) sug- N gested that alterations of the expression pattern of these genes could be involved in several pathologies.

nov and CTGF genes have been assigned $\stackrel{\oplus}{+}$ to chromosomes $8 \mathrm{q} 24.1$ and $6 \mathrm{q} 23.1$, 7 respectively. ${ }^{20}$ In this report we show that the human cyr61 gene $($ cyr61H) is conserved, maps to chromosome $1 \mathrm{p} 22.3$, and is expressed $\mathbb{D}$ differentially in tumours and tumour cell lines derived from the nervous system.

\section{Methods}

CELL CULTURE AND TISSUES

The neuroblastomas analysed were isolated and characterised in the IGR, Villejuif (Bénard et al, unpublished data). Pathological diagnosis determined one undifferentiated neuroblastoma (stage IV), two ganglioneuroblastomas (stage III), and three ganglioneuromas (local). 
Glioma cell lines were established from fresh tumour specimens. ${ }^{21}$ The tumours were obtained from patients between 4 and 71 years of age. Classification of the tumours was performed according to WHO guidelines. The tumour cell lines analysed in this study are derived from tumours of WHO grade 3 or 4 and are referred to as high grade hereafter. ${ }^{22}$ The cell lines were maintained at $37^{\circ} \mathrm{C}$ in Earle's modified minimal essential medium (MEM) containing $10 \%$ fetal calf serum in an $8 \% \mathrm{CO}_{2}$ humidified atmosphere.

\section{NUCLEOTIDE SEQUENCING}

The $2.0 \mathrm{~kb}$ EcoRI insert derived from $16 \lambda \mathrm{H}$ recombinant phage was further subcloned in Bluescript $\mathrm{pBS} / \mathrm{KS}$ plasmid (Stratagene Cloning Systems, La Jolla, California, USA) to generate pCYR61H and sequenced by the dideoxy chain termination method ${ }^{23}$ in the presence of $\left(\alpha{ }^{35} \mathrm{~S}\right)$ dATP and T7 polymerase (Pharmacia, Orsay, France). Sequence data treatments were performed using the computer facilities at Infobiogen (Villejuif, France).

\section{DNA AND RNA PURIFICATION, SOUTHERN AND NORTHERN BLOTTING}

Procedures for DNA and RNA purification from tissues and cell cultures and for Southern and northern blotting are described elsewhere. ${ }^{24}$ The Southern blots were hybridised to the $2.0 \mathrm{~kb}$ EcoR1 fragment derived from the pcyr $61 \mathrm{H}$ clone. The northern blots were hybridised either to the $1.0 \mathrm{~kb}$ NcoIHindIII fragment derived from the cyr61H clone, to the $3.5 \mathrm{~kb}$ BglII-BamHI fragment from the $\mathrm{pBH} 7$ novH clone (probe $\mathrm{pBH} 7 / \mathrm{BB}),{ }^{25}$ or to the $700 \mathrm{bp}$ PstI fragment derived from the pS6 CTGF clone pS6 (probe pS6/PSP07). ${ }^{25}$

IN SITU HYBRIDISATION

The details of chromosome preparation and banding, probe labelling, and hybridisation have been described previously. ${ }^{26}{ }^{27}$ Probes labelled with 11-UTP (Bio-Rad Laboratories, Ivry sur Seine, France) were detected by indirect immunofluorescence using a fluorescein conjugated antibody. Probes were annealed with total DNA in order to avoid hybrisation of repeated sequences contained in the genomic pBB6.5 and pEE6.2 probes. The final concentration of total DNA in the hybridisation mixture was $20 \mu \mathrm{g} / \mathrm{ml}$, slides were annealed at $37^{\circ} \mathrm{C}$ for 10 minutes.

\section{Results}

Screening of a normal human genomic placental library (Clontech, Montigny le Bretonneux, France) and of a HeLa cell cDNA library (Clontech), using murine pcyr61 $\mathrm{cDNA}^{1}$ as a probe, allowed us to isolate several $\lambda$ recombinant clones whose representatives are $\lambda \mathrm{Hu} 11$ genomic DNA and $\lambda 161 \mathrm{H}$ cDNA (fig 1). As reported previously for the murine cyr61 gene, ${ }^{28}$ the entire cyr61H coding region spans about $3 \mathrm{~kb}$ of DNA (fig 1 ).

Comparison of the pcyr61H cDNA nucleotide sequence with the murine pcyr61 and the chicken CEF10 cDNA sequences ${ }^{3}$ revealed an overall identity of $82 \%$ and $77 \%$, respectively. The consensus sequences TTATAAA, which

Table 1 Analysis of human markers: chromosomes, enzyme PGM1, and CYR61H EcoRI sequences (6.2 kb) in 25 independent human-rodent hybrids

\begin{tabular}{|c|c|c|c|c|c|c|c|c|c|c|c|c|c|c|c|c|c|c|c|c|c|c|c|c|c|c|}
\hline \multirow[b]{2}{*}{ Hybrids } & \multicolumn{24}{|c|}{ Chromosomes } & \multirow{2}{*}{$\begin{array}{l}E c o R I \\
6.2 \mathrm{~kb}\end{array}$} & \multirow[b]{2}{*}{ PGM1 } \\
\hline & 1 & 2 & 3 & 4 & 5 & 6 & 7 & 8 & 9 & 10 & 11 & 12 & 13 & 14 & 15 & 16 & 17 & 18 & 19 & 20 & 21 & 22 & $X$ & $Y$ & & \\
\hline \multicolumn{27}{|l|}{ Man-mouse } \\
\hline L.53K & 1 & + & I & + & + & - & + & + & - & - & + & - & - & - & - & - & + & - & - & / & - & - & I & $\star$ & + & + \\
\hline L. $53 \mathrm{~N}$ & - & - & + & / & - & + & - & + & - & - & - & + & l & - & - & - & + & - & + & + & + & - & - & $\star$ & - & - \\
\hline LA. 56E & - & + & + & I & + & + & + & - & - & - & + & - & - & - & I & 1 & + & - & + & + & + & 1 & + & $\star$ & - & - \\
\hline LA.56G & + & + & + & - & + & + & + & + & - & + & 1 & + & + & - & - & + & + & + & + & + & + & + & + & $\star$ & + & + \\
\hline LA.56I & - & + & + & I & + & - & + & + & - & - & - & + & + & 1 & - & + & + & + & - & + & + & + & - & $\star$ & - & - \\
\hline LA. $56 \mathrm{U}$ & + & + & - & + & + & - & + & + & - & 1 & + & + & - & - & + & + & + & + & + & + & + & + & 1 & * & + & + \\
\hline \multicolumn{27}{|l|}{ Man-hamster } \\
\hline V.106 & - & - & - & - & I & - & - & - & - & + & - & - & - & - & + & - & - & - & 1 & + & + & I & + & + & - & - \\
\hline CH.106IV & - & - & - & - & - & + & - & + & - & - & + & + & - & - & - & - & - & - & - & + & 1 & + & + & - & - & - \\
\hline CH.BLD & - & - & - & + & + & + & - & + & - & + & + & - & + & + & - & - & - & - & + & - & + & - & 1 & $\star$ & - & - \\
\hline CH.BLE & - & - & + & 1 & - & + & - & + & I & - & - & - & 1 & + & + & + & - & I & + & - & - & - & - & $\star$ & - & - \\
\hline CH.BLH & + & - & + & + & - & + & - & 1 & + & 1 & + & + & + & + & + & + & - & + & + & + & + & + & + & $\star$ & + & + \\
\hline CH.BLI & + & - & - & + & 1 & - & - & + & - & - & + & + & - & - & - & - & - & + & + & - & - & - & + & $\star$ & + & + \\
\hline CH.BLN & + & - & - & + & + & + & + & - & + & - & + & - & - & - & - & + & - & I & + & + & + & + & + & $\star$ & + & + \\
\hline CH.56F & - & - & - & - & - & - & - & + & - & - & - & - & - & + & + & + & - & - & + & - & + & - & + & $\star$ & - & - \\
\hline CH.56X & + & + & + & I & + & + & - & + & + & - & - & + & - & - & - & - & - & + & + & - & - & + & - & $\star$ & + & + \\
\hline CH.34E & - & - & + & I & + & - & - & + & + & - & + & + & - & + & - & + & 1 & - & + & + & + & - & $\star$ & - & - & - \\
\hline CH.34G & - & - & - & - & - & - & - & - & - & - & - & - & - & - & - & - & I & - & - & - & + & - & $\star$ & - & - & - \\
\hline CH.34S & - & - & - & - & - & + & - & 1 & - & + & + & + & - & + & - & 1 & - & - & - & + & + & + & $\star$ & - & - & - \\
\hline CH.34V & + & - & + & + & + & - & - & + & + & - & + & + & + & + & I & I & - & + & + & + & - & - & $\star$ & - & + & + \\
\hline CH.34X & + & - & i & - & - & + & - & + & + & 1 & + & + & + & - & + & + & - & + & - & - & + & - & $\star$ & - & + & + \\
\hline CH.34FU & - & - & + & + & - & - & - & + & - & - & - & - & - & + & - & 1 & - & - & 1 & + & - & - & $\star$ & + & - & - \\
\hline CH.34GT & - & - & - & + & - & + & - & + & 1 & + & - & + & + & + & - & - & - & + & - & 1 & + & - & $\star$ & - & - & - \\
\hline \multicolumn{27}{|c|}{ Discordant } \\
\hline CYR61H(\%) & 8 & 40 & 48 & 32 & 26 & 48 & 36 & 41 & 32 & 43 & 29 & 52 & 35 & 63 & 35 & 38 & 52 & 14 & 39 & 50 & 59 & 26 & 43 & 44 & & 0 \\
\hline
\end{tabular}

Hybrid cell lines have been described by Nguyen $e t$ al. ${ }^{31}$ Karyotype analyses of each cell line and reference enzyme marker studies were done at the time of DNA preparation. In some cases, hybrid content differed from the initial description by Nguyen et al. Analyses for phosphoglucomutase 1 (PGM1) a chromosome 1 reference marker was performed according to Van Someren et al. ${ }^{41}$

Chromosomes: +, chromosome detected at least in $30 \%$ of cells; -, chromosome not detected; /, chromosome detected in fewer than $30 \%$ of cells, not scored for mapping; ${ }^{\star}$, chromosome absent in the human parental strains.

Enzyme PGM1 and CYR61H EcoRI sequence: + , the human marker is present in hybrid cells; -, the humian marker is absent in hybrid cells. 


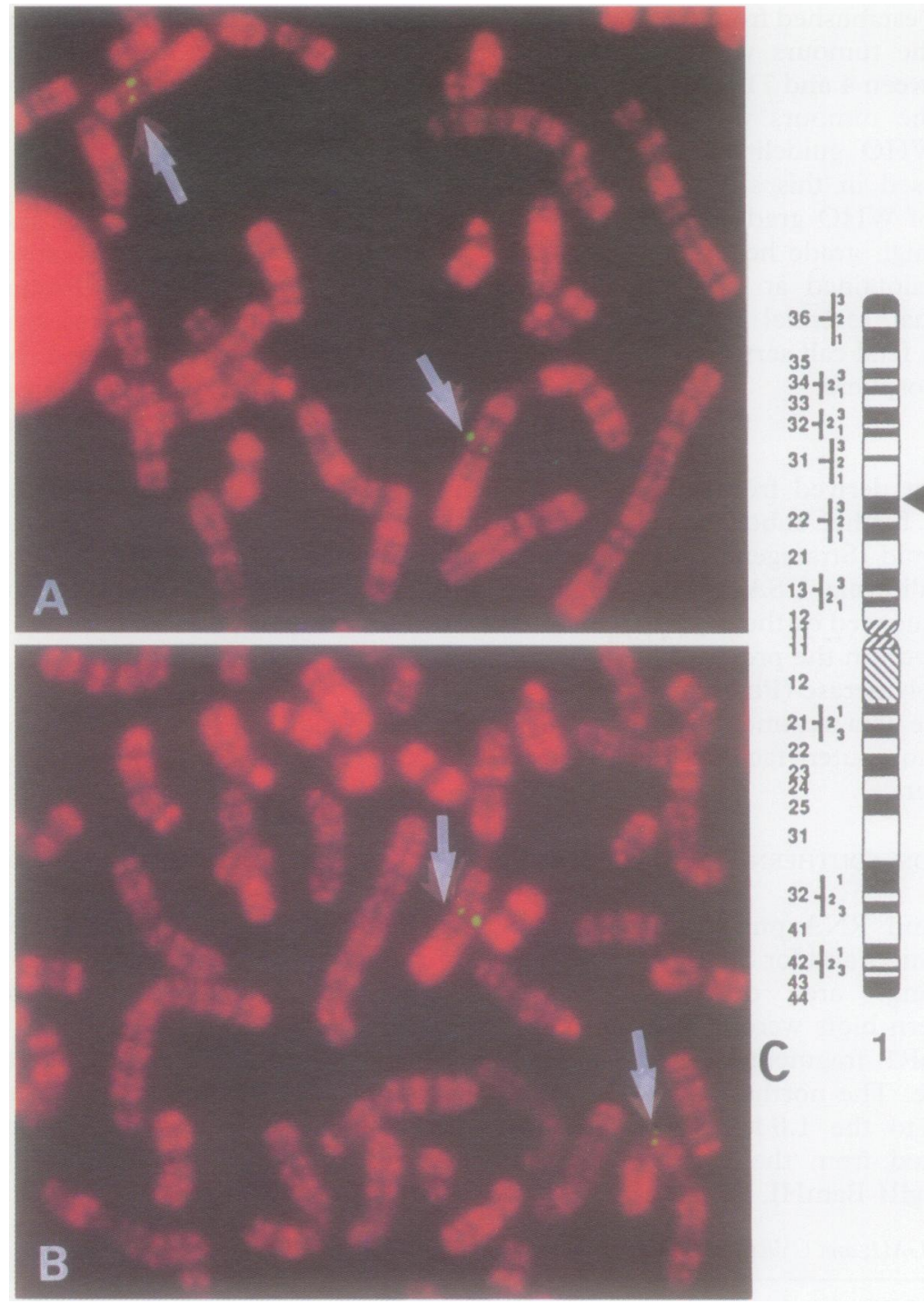

Figure 4 In situ hybridisation of biotinylated cyr61H specific probes on human metaphase chromosomes. Chromosomes were counterstained with propidium iodide. (A) Hybridisation with the $p B B 6.5$ probe. (B) Hybridisation with the $p E E 6.2$ probe. Arrows indicate fluorescent spots in 1p22.3. (C) Schematic representation of the relative position of the cyr61 gene and a longitudinal map (mapped in relation to chromosome banding) of chromosome 1 .

confer instability to transcripts, ${ }^{29}$ are represented in the human cyr61 gene at positions 1896-1903 and 1990-1997, and only one of the $49 \mathrm{bp}$ repeats present in the murine cyr61 3 untranslated region ${ }^{28}$ is partially conserved in the human gene $(39 / 49 \mathrm{bp})$. The predicted amino acid sequence of the longest open reading frame of pcyr61H revealed that the 381 amino acid CYR61H protein was $91 \%$ and $81 \%$ identical to murine CYR61 and chicken CEF10. Therefore, pcyr61H is likely to represent the human homologue of the murine cyr61 gene and the chicken CEF10 gene. Prediction of post-translational modifications revealed that CYR61/CEF10 proteins were likely to undergo several specific phosphorylations in addition to the common ones (fig 1 ). It is worth noting that, in exon 4 , the stretch of amino acids from positions 166 to 227 , which lies between the VWC and TSP1 modules, ${ }^{13}$ is the least conserved between the CYR61H, CYR61, and CEF10 proteins. As shown in fig 2 the predicted secondary structure and hydrophobicity profile ${ }^{30}$ of these three proteins revealed significant topological differences.
Therefore, these observed differences might confer particular biological properties to each of the three CYR61H, CYR61, and CEF10 proteins.

Comparison of the CYR61H protein se quence with that of other related proteins of the same family also revealed a high degree of con servation of the four putative IGFBP, VWC TSP1, and CT domains .

As a first step in our search for rearrange? ment or alterations of the cyr61H gene in human pathologies, we have performed physical mapping of the cyr61H gene.

Southern blot hybridisations with the्s pcyr61H probe were performed on a series of 25 rodent-human hybrid DNA samples ${ }^{3 \mathrm{~L}}$ digested with EcoRI. The human cyr6 $\overrightarrow{5}$ specific sequences were detected in a $6.2 \mathrm{~kb}$ fragment (fig 3). The same probe also revealed two cyr61 specific fragments of $7.6 \mathrm{~kb}$ and $2.5 \mathrm{~kb}$ in murine and hamster DNA, respec tively. In human-rodent hybrids a positive cor relation was observed between cyr61H se응 quences and the phosphoglucomutase 1 gene (PGM1), a well known chromosome 1 referD ence marker. ${ }^{32}$ Among 25 independent hybrid analysed, 11 were positive and 14 were negative for these two markers. No discordant result was observed between cyr61H specific sequences and PGM1 (table 1). The percentage oft discordant results were $8 \%$ for chromosome and between $8 \%$ and $63 \%$ for the othep chromosomes (table 1). According to the exclusion criterion (marker absent/chromo some present), all chromosomes other tharo chromosome 1 could be excluded for the pres ence of cyr61 specific sequences. In hybrids negative for cyr61H sequences, only chromo some 1 was absent. Taken together, these dat indicate that the cyr61H gene is localised on chromosome 1.

Non-radioactive in situ hybridisations were performed using both pBB6.5 and pEE6.2 as probes on metaphase chromosomes obtained from human lymphocyte cultures of norma? donors (fig 4). The frequency of metaphases with chromosomes showing one fluorescen spot on one chromatid was about $60 \%$. These fluorescent spots were observed systematically in the distal part of band p22.3 of chromosomen 1 , therefore assigning the cyr61H gene to this band.

Alterations and deletions of the distal part of chromosome $1 \mathrm{p}$ have been associated with sev eral human tumours of neuroectodermal ori gin, including neuroblastoma. ${ }^{33}$ Concentra=0 tions of cyr61 $\mathrm{H}$ mRNA varied from one type of neuroblastoma to another (fig 5). While cyr61H expression could be detected easily in ganglioneuromas $(322,321$, and 320) and in ganglioneuroblastomas ( 345 and 175), a much lower concentration of cyr61H RNA was detected in neuroblastoma 104. Variations of CTGF and novH expression were observe also in these tumours. Except in neuroblastoma 104, in which cyr61H, CTGF, and novH were expressed at very low concentrations, no obvious correlation could be drawn with respect to the relative expression of these three genes. 

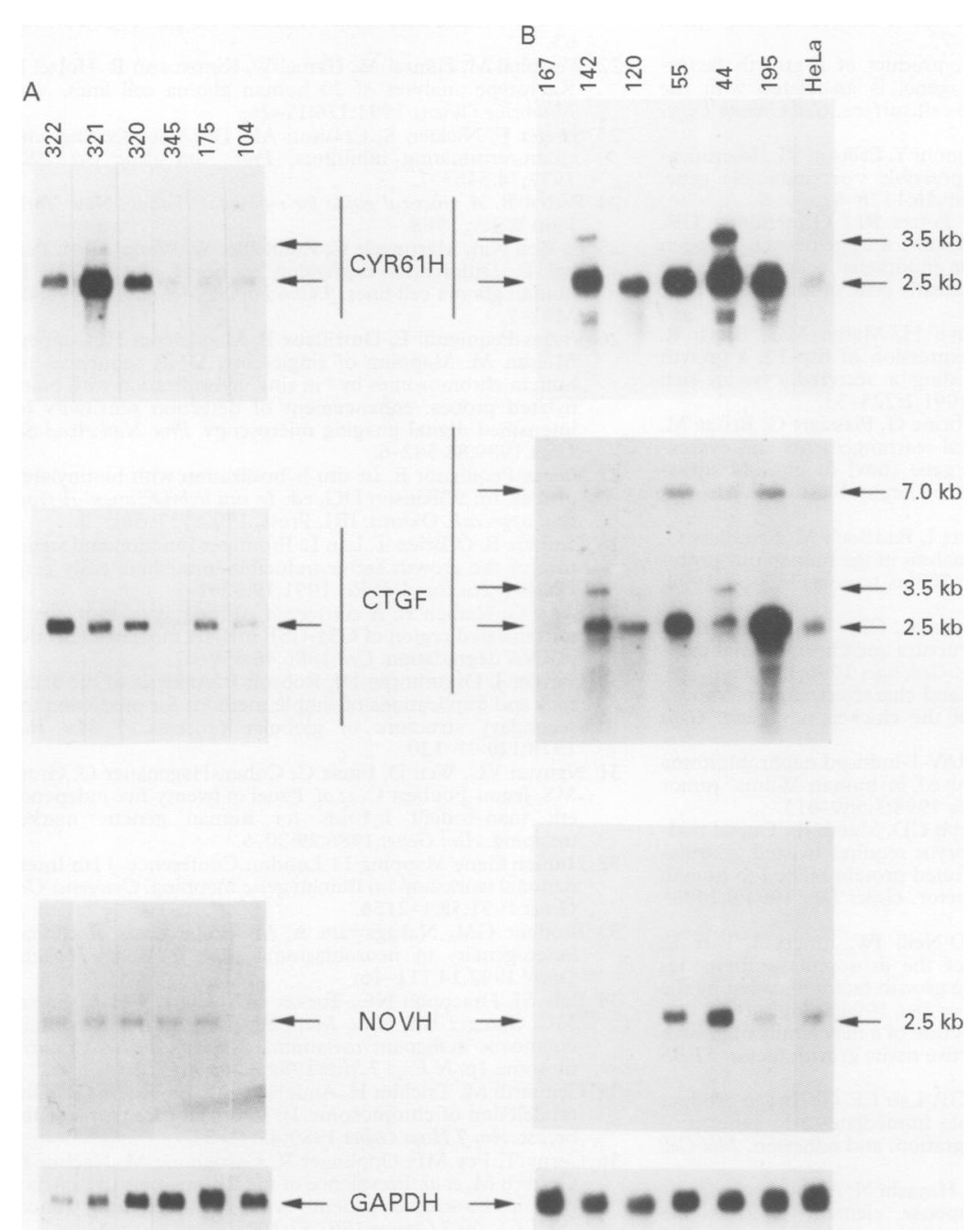

Figure 5 Expression of cyr61H, CTGF, and novH in human neuroblastoma and glioma cell lines. Total RNA samples $(20 \mu \mathrm{g})$ were electrophoresed in $1 \%$ agarose gels, transferred to Nytran ${ }^{+}$membranes (Schleicher and Schuell, Strasbourg, France) and hybridised with ${ }^{32} \mathrm{P}$ labelled cyr61H,CTGF, or nov $H$ specific probes. The amount of $R N A$ transferred in each lane was normalised following hybridisation with a human GAPDH probe (Clontech). (A) Neuroblastomas; (B) glioma cell lines.

Different concentrations of cyr61H mRNA species were detected also in human glioblastoma derived cell lines (fig 5 ). The expression of cyr61H was detectable in all glioblastoma cell lines studied but one (167). It is worth noting that neither CTGF nor novH could be detected in this glioma cell line.

Two different cyr61H mRNA species were detected in the different neuroblastomas and glioblastomas. In addition to the major $2.5 \mathrm{~kb}$ mRNA species, a less abundant $3.5 \mathrm{~kb}$ mRNA species was detected in a subset of these cell lines. As already reported ${ }^{25}$ for the $3.5 \mathrm{~kb}$ and $7.0 \mathrm{~kb}$ CTGF mRNA species which are expressed in these cell lines, no obvious correlation was observed between the concentrations of the $2.5 \mathrm{~kb}$ and $3.5 \mathrm{~kb}$ cyr61 $\mathrm{H}$ mRNA species expressed. Because the complete cyr61H cDNA probe detected only a $6.2 \mathrm{~kb}$ DNA fragment and only one chromosomal localisation was revealed by in situ hybridisation, it was concluded that the $3.5 \mathrm{~kb}$ mRNA species is most likely the result of an alternative splicing event. The observation that the $3.5 \mathrm{~kb}$ mRNA species of both cyr61H and CTGF are expressed in the same glioblastomas might be of biological relevance.

\section{Discussion}

Although alterations of chromosome 1p have been associated with several human tumours of neuroectodermal origin including neuroblastoma, ${ }^{33}$ melanoma, ${ }^{34}$ breast cancer, ${ }^{35}$ and small lung carcinoma ${ }^{36}$ only a few human tumour pathologies have been correlated thus far with abnormalities of the $1 \mathrm{p} 22$ region. A $(1 ; 10)(p 22 ; q 12)$ constitutional translocation was reported in a patient with stage $4 S$ neuroblastoma. ${ }^{37}$

A larger survey of neuroblastoma samples would be required to establish a correlation between cyr $61 \mathrm{H}$ expression and the stage of neuroblastoma malignancy. However, it is worth noting that cyr61H expression was greatest in ganglioneuromas, which represent a benign stage of neuroblastoma and are composed of fully mature ganglion cells embedded in nerve fibres. ${ }^{38}$ Therefore, considering that the CYR61 protein plays a role in cell proliferation and adhesion, ${ }^{14}$ it is possible that genetic alterations of $1 \mathrm{p} 22$ that affect cyr61H expression might participate in the development of these tumours.

Downregulation of cyr61H expression was also reported in rhabdomyosarcomas. ${ }^{39}$ Analysis of substractive hybridisations performed between human primary myoblasts and an embryonal rhabdomyosarcoma cell line has led to the isolation, from myoblasts, of a fragment of cDNA (A33210) ${ }^{39}$ whose sequence is $100 \%$ identical to positions $544-847$ of the cyr61H gene. Thus, it appears that inhibition of cyr $61 \mathrm{H}$ expression might also be of importance in the maintenance or progression of these tumours.

In human glioblastoma cell lines different levels of cyr61H, CTGF, and novH expression have been observed. Because CTGF, cyr61, and nov might have an antagonistic effect on cell growth, ${ }^{10}$ it is possible that a balance between expression of these three genes is required to modulate the proliferation and/or differentiation state of the cells.

Because cyr61 expression has been shown to correlate with chondrogenesis during mouse development, ${ }^{18}$ it would be worth examining whether cyr61H , nov, and CTGF are altered in human pathologies derived from cartilage or bone, and whether abnormalities of the chromosomal regions $1 \mathrm{p} 22.3$, 8q24.1, and 6q23.1 are observed in such pathologies.

\section{Addendum}

Sequence data from this article has been deposited with the EMBL/GenBank Data Libraries under Accession number Y11307. While this manuscript was being submitted, Jay et $a l^{42}$ reported an approximate localisation of the human cyr61 to chromosome $1 \mathrm{p} 22-\mathrm{p} 31$.

We thank Dr J Benard for the gift of neuroblastomas samples This work was supported by grants from Association pour la Recherche contre le Cancer (ARC), Ligue Nationale Contre le Cancer (Comités de Paris, du Cher), and Fondation pour la Recherche Médicale. 
1 O'Brien TP, Yang GP, Sanders L, Lau LF. Expression of CYR61, a growth factor-inducible immediate-early gene. Mol Cell Biol 1990;10:3569-77.

2 Yang GP, Lau LF. CYR61, product of a growth factorinducible immediate early gene, is associated with the extracellular matrix and the cell surface. Cell Growth Differ 1991;2:351-7.

3 Simmons DL, Levy DB, Yannoni Y, Erikson RL. Identification of a phorbol ester-repressible $\mathrm{v}$-src-inducible gene. Proc Natl Acad Sci USA 1989;86:1178-82.

4 Bradham DM, Igarashi A, Potter RL, Grotendorst GR Connective tissue growth factor: a cysteine-rich mitogen secreted by human vascular endothelial cells is related to the SRC-induced immediate early gene product CEF-10.尹 Cell Biol 1991;114:1285-94.

5 Ryseck RP, Macdonald-Bravo H, Mattei MG, Bravo R Structure, mapping, and expression of fisp-12, a growth factor-inducible gene encoding a secreted cysteine-rich protein. Cell Growth Differ 1991;2:225-33.

6 Joliot V, Martinerie C, Dambrine G, Plassiart G, Brisac M Crochet J, Perbal B. Proviral rearrangements and overexpression of a new cellular gene (nov) in myeloblastosisassociated virus type 1 -induced nephroblastomas. Mol Cell Biol 1992;12:10-21.

7 Martinerie C, Huff V, Joubert I, Badzioch M, Saunders G Strong L, et al. Structural analysis of the human nov protooncogene and expression in Wilms tumor. Oncogene 1994 9:2729-32.

8 Snaith M, Natarajan D, Taylor L, Choi C, Martinerie C, Perbal B, et al. Genomic structure and chromosomal mapping of the mouse nov gene. Genomics 1996;38:425--8.

9 Ying Z, King ML. Isolation and characterization of xnov, a Xenopus laevis ortholog of the chicken nov gene. Gene 1996;171:243-8.

10 Perbal B. Contribution of MAV-1-induced nephroblastoma to the study of genes involved in human Wilms' tumor development. Crit Rev Oncog 1994;5:589-613.

11 Mason ED, Konard KD, Webb CD, Marsh JL. Dorsal midline fate in Drosophila embryos requires twisted gastrulation, a gene encoding a secreted protein related to human connective tissue growth factor. Genes Dev 1994;8:1489 501.

12 Francois V, Solloway M, O'Neill JW, Emery J, Bier E. Dorsal-ventral patterning of the drosophila embryo depends on a putative negative growth factor encoded by the pends on a putative negative growth factor encoded
short gastrulation gene. Genes Dev 1994;8:2602-16.

13 Bork P. The modular architecture of a new family of growth regulators related to connective tissue growth factor. FEB. Lett 1993;327:125-30

14 Kireeva ML, Mo FE, Yang GP, Lau LF. CYR61, a product of a growth factor-inducible immediate-early gene, promotes cell proliferation, migration, and adhesion. $\mathrm{Mol} C \mathrm{e}^{\prime}$ Biol 1996;16:1326-34.

15 Grotendorst GR, Okochi $\mathrm{H}$, Hayashi N. A novel transforming growth factor $\beta$ response element controls the ing growth factor $\beta$ response element controls the Growth Differ 1996;7:469-80.

16 Kothapalli D, Frazier KS, Welply A, Segarini PR, Grotendorst GR. Transforming growth factor $b$ induce anchorage-independent growth of NRK fibroblasts via connective tissue growth factor-dependent signalling pathway. Cell Growth Differ 1997;8:61-8.

17 Scholz G, Martinerie C, Perbal B, Hanafusa H. Transcriptional down regulation of the nov proto-oncogene in fibroblasts transformed by p60v-src. Mol Cell Biol 1996;16: 481-6.

18 O'Brien TP, Lau LF. Expression of the growth factorinducible immediate early gene CYR61 correlates with chondrogenesis during mouse embryonic development. Cell Growth Differ 1992;3:645-54.

19 Chevalier G, Perbal B. Altérations génétiques associées à la différenciation pathologique des tumeurs de Wilms. Bull Cancer. [In press.]

20 Martinerie C, Viegas-Pequignot E, Guenard I, Dutrillaux B, Nguyen VC, Bernheim A, et al. Physical mapping of human loci homologous to the chicken nov proto-oncogene. Oncogene 1992;7:2529-34.

21 Westphal M, Hansel M, Brunken M, Köning A, Köppen JA Herrmann HD. Initiation of primary cell cultures from human intracranial tumors on extracellular matrix from bovine corneal endothelial cells. Exp Cell Biol 1987;55:15263.

22 Westphal M, Hänsel M, Hamel W, Kunzmann R, Hölzel F. Karyotype analyses of 20 human glioma cell lines. Acta Neurochir (Wien) 1994;126:17-26.

23 Sanger F, Nicklen S, Coulson AR. DNA sequencing with 으 chain-terminating inhibitors. Proc Natl Acad Sci USA 1977;74:5463-7.

24 Perbal B. A practical guide for molecular cloning. New York: John Wiley, 1988

25 Li Wen Xin, Martinerie C, Zumkeller W, Westphal M, Per- $\overrightarrow{\overline{\mathbf{C}}}$ bal B. Differential expression of novH and CTGF in human glioma cell lines. F Clin Pathol: Mol Pathol 1996;49: M91-7.

26 Viegas-Pequignot E, Dutrillaux B, Magdelenat H, CoppeyMoisan M. Mapping of single-copy DNA sequences on human chromosomes by "in situ" hybridization with bioti- $\mathbb{D}$ nylated probes: enhancement of detection sensitivity by intensified digital-imaging microscopy. Proc Natl Acad Sci on intensified digital-imagi

27 Viegas-Pequignot E. In situ hybridization with biotinylated $\vec{\circ}$ probes. In: Wilkinson DG, ed. In situ hybridization. A practical approach. Oxford: IRL Press, 1992:137-58.

28 Latinkic B, O'Brien T, Lau L. Promoter function and structure of the growth factor inducible-immediate early gene $\exists$ CYR61. Nucleic Acid Res 1991;19:3261-7.

29 Shaw G, Kamen R. A conserved AU sequence from the 3' untranslated region of GM-CSF mRNA mediates selective mRNA degradation. Cell 1986;46:659-67.

30 Garnier J, Osguthorpe DJ, Robson B. Analysis of the accuracy and implications of simple methods for predicting the secondary structure of globular proteins. $7 \mathrm{Mol}$ Biol 1978;120:97 120 .

31 Nguyen VC, Weil D, Finaz C, Cohen-Hagenauer O, Gross MS, Jegou-Foubert C, et al. Panel of twenty-five independent man-rodent hybrids for human genetic marker mapping. Ann Genet 1986;29:20-6.

32 Human Gene Mapping 11 London Conference. 11 th International workshop on human gene mapping. Cytogenet Cell Genet 1991;58:1-2156.

33 Brodeur GM, Nakagawara A. Molecular basis of clinical heterogeneity in neuroblastoma. Am $\mathcal{f}$ Pediatr Hematol Oncol 1992;14:111-16.

34 Bale SJ, Dracopoli NC, Tucker MA, Clark WH Jr, Fraser. MC, Stanger BZ, et al. Mapping the gene for hereditary cutaneous malignant melanoma-dysplasic nevus to chromosome lp. N Engl f Med 1989;320:1367-72.

35 Genuardi M, Tsichira H, Anderson DE, Saunders GF. Distal deletion of chromosome $1 \mathrm{p}$ in ductal carcinoma of the breast. Am f Hum Genet 1989;45:73-82.

36 Cerny T, Fey MF, Opplinger R, Castiglione M, Nacbur B, Gertsch $M$, et al. Prevalence of the Rhesus-negative pheno- $\vec{F}$ type in Caucasian patients with small-cell lung cancer $\vec{O}$ (SCLC). Int $\mathcal{F}$ Cancer 1992;52:504-6.

37 Mead RS, Cowell JK. Molecular characterization of a $(1 ; 10)(\mathrm{p} 22 ; \mathrm{q} 21)$ constitutional translocation from a patient with neuroblastoma. Cancer Genet Cytogenet 1992;81:151 7 .

38 Moll M, LaQuaglia M, Bénard J, Riou G. Wild-type p53 protein indergoes cytoplasmic sequestration in undifferentiated neuroblastomas but not in differentiated tumors. Proc Natl Acad Sci USA 1995;92:4407-11.

39 Genini M, Schwalbe P, Scholl FA, Schafer BW. Isolation of 8 genes differentially expressed in human primary myoblasts and embryonal rhabdomyosarcoma. Int $\mathcal{F}$ Cancer 1996;66: $571-7$.

40 Higgins DG, Sharp PM. Clustal: a package for performing sequence alignment on a microcomputer. Gene 1988;73: $237-57$.

ren $\mathrm{H}$, van Henegouven $\mathrm{HB}$, Los W, WurzerFigurelli E, Doppert B, Vervolet $\mathrm{M}$, et al. Enzyme ô electrophoresis on cellulose acetate gel. Hum Genet 1994;25:189-201.

42 Jay P, Bergé-Lefranc JL, Marsollier C, Méjean C, Taviaux S, N Berta P. The human growth factor-inducible immediate early gene, CYR61, maps to chromosome lp. Oncogene 1997; 14:1753-7. 